\title{
Thrombocytopenia in COVID-19: pathophysiology matters
}

\author{
Eleni Gavriilaki ${ }^{1}$ (D) Ioanna Sakellari $^{1} \cdot$ Maria Gavriilaki $^{2} \cdot$ Achilles Anagnostopoulos $^{1}$
}

Received: 1 June 2020 / Accepted: 13 July 2020 / Published online: 18 July 2020

(C) Springer-Verlag GmbH Germany, part of Springer Nature 2020

Dear Editor,

We read with great interest the recent review of thrombocytopenia mechanisms in COVID-19 [1]. The authors meticulously analyze mechanisms raising questions on potential therapeutic targets. Taking into account the rapidly accumulating knowledge in COVID-19, our correspondence aims to highlight an important pathophysiological aspect of thrombocytopenia that simultaneously acts as a therapeutic target: complement activation.

Indeed, recent evidence suggests that severe COVID-19 resembles the pathophysiology and phenotype of complement-mediated thrombotic microangiopathies (TMAs) [2]. Thrombocytopenia is one of the major characteristics of TMAs, along with microangiopathic hemolytic anemia, and organ damage, such as neurological, renal, and cardiac dysfunction. Recent studies have suggested cells with high expression of angiotensin-converting enzyme 2 (ACE2) are target cells of COVID-19. Such cells include cardiac pericytes. Patients with heart failure have increased ACE2 expression and are therefore expected to be of high risk of cardiac injury due to COVID-19 [3]. In a similar manner, ACE2 is highly expressed on podocytes and tubule epithelial cells of the kidney, as well as in the vasculature of neurons [4]. A recent study also suggested SARS-CoV-2 (severe acute respiratory syndrome coronavirus 2) tropism for the kidney [5]. Taken together, these data suggest that COVID-19 causes organ damage, similar to that of TMA.

Complement activation plays a central role in the pathophysiology of TMAs that have been categorized into the wider group of complement-mediated TMAs [5]. Studies

Eleni Gavriilaki

elenicelli@yahoo.gr

1 Hematology Department—BMT Unit, G Papanicolaou Hospital, Exochi, 57010 Thessaloniki, Greece

2 Laboratory of Clinical Neurophysiology, AHEPA Hospital, Aristotle University of Thessaloniki, Thessaloniki, Greece of previous coronaviruses have established activation of complement component $\mathrm{C} 3$ in the pathophysiology of ARDS (acute respiratory distress syndrome) [6]. In severe COVID-19, complement activation products, including C5b-9, C4d, and MAPS-2 (mannose-binding proteinassociated serine protease 2), have been detected in the microvasculature of lung and skin biopsies [7]. Complement activation products $(\mathrm{C} 3 \mathrm{~b}, \mathrm{iC} 3 \mathrm{~b}, \mathrm{C} 3 \mathrm{dg}$, and C4d) have been also found increased on circulating erythrocytes from COVID-19 patients using flow cytometry [8]. Furthermore, two recent preprint studies have shown additional evidence of complement activation. Gao et al. detected excessive proximal and terminal complement activation that was alleviated by anti-C5a treatment [9]. Skendros et al reported evidence of terminal complement activation and NET (neutrophil extracellular trap) formation in COVID-19 immunothrombosis. Interestingly, complement inhibition at the level of $\mathrm{C} 3$ disrupted $\mathrm{TF}$ expression in neutrophils [10].

Since effective treatment is available for complementmediated TMA [11], recognition of complement activation in COVID-19 simultaneously renders a complement therapeutic target. The first-in-class terminal complement inhibitor, eculizumab, has been administered in four patients with severe COVID-19, leading to successful disease outcomes [12]. Furthermore, the compstatin-based inhibitor AMY-101 has also shown safety and efficacy of $\mathrm{C} 3$ inhibition in severe COVID-19 [13]. Ongoing clinical trials with ravulizumab (a long-acting $\mathrm{C} 5$ inhibitor) will prove safety and efficacy in this setting. Although cost-effectiveness analyses are not expected to be performed, it should be noted that the cost of FDAapproved complement inhibitors (eculizumab and ravulizumab) cannot be overlooked. However, the nextgeneration complement therapeutics are expected to overcome this challenge [14].

These data suggest that thrombocytopenia in severe COVID-19 could be considered through the prism of a complement-mediated TMA. In such cases, complement inhibition is expected to be safe and effective. Since the duration 
of the pandemic still remains unknown, ongoing studies are eagerly expected to confirm the role of complement activation and inhibition in this setting.

Acknowledgments Given the limited number of references allowed in this perspective, the authors thank the colleagues who are not specifically cited for their contribution and their understanding.

Authors' contribution E.G. and E.G. drafted and edited the manuscript. I.S and A.A edited and approved the final manuscript.

\section{Compliance with ethical standards}

Conflicts of interest The authors declare that they have no conflict of interest.

Ethical approval Not applicable.

\section{References}

1. Xu P, Zhou Q, Xu J (2020) Mechanism of thrombocytopenia in COVID-19 patients. Ann Hematol 99(6):1205-1208. https://doi. org/10.1007/s00277-020-04019-0

2. Gavriilaki E, Brodsky RA (2020) Severe COVID-19 infection and thrombotic microangiopathy: success doesn't come easily. Br J Haematol 189:e227-e230. https://doi.org/10.1111/bjh.16783

3. Chen L, Li X, Chen M, Feng Y, Xiong C (2020) The ACE2 expression in human heart indicates new potential mechanism of heart injury among patients infected with SARS-CoV-2. Cardiovasc Res 116(6):1097-1100. https://doi.org/10.1093/cvr/cvaa078

4. Netland J, Meyerholz DK, Moore S, Cassell M, Perlman S (2008) Severe acute respiratory syndrome coronavirus infection causes neuronal death in the absence of encephalitis in mice transgenic for human ACE2. J Virol 82(15):7264-7275. https://doi.org/10. 1128/JVI.00737-08

5. Gavriilaki E, Anagnostopoulos A, Mastellos DC (2019) Complement in thrombotic microangiopathies: unraveling Ariadne's thread Into the labyrinth of complement therapeutics. Front Immunol 10:337. https://doi.org/10.3389/fimmu.2019.00337
6. Risitano AM, Mastellos DC, Huber-Lang M, Yancopoulou D, Garlanda C, Ciceri F, Lambris JD (2020) Complement as a target in COVID-19? Nat Rev Immunol 20:343-344. https://doi.org/10. 1038/s41577-020-0320-7

7. Magro C, Mulvey JJ, Berlin D, Nuovo G, Salvatore S, Harp J, Baxter-Stoltzfus A, Laurence J (2020) Complement associated microvascular injury and thrombosis in the pathogenesis of severe COVID-19 infection: a report of five cases. Transl Res 220:1-13. https://doi.org/10.1016/j.trsl.2020.04.007

8. Lam LM, Murphy SJ, Kuri-Cervantes L, Weisman AR, Ittner CAG, Reilly JP et al (2020) Erythrocytes reveal complement activation in patients with COVID-19. medRxiv. https://doi.org/10. 1101/2020.05.20.20104398.

9. Gao T, Hu M, Zhang X, Li H, Zhu L, Liu H et al. Highly pathogenic coronavirus $\mathrm{N}$ protein aggravates lung injury by MASP-2-mediated complement over-activation. medRxiv. 2020 : 2020.03.29.20041962. https://doi.org/10.1101/2020.03.29. 20041962

10. Skendros P, Mitsios A, Chrysanthopoulou A, Mastellos DC, Metallidis S, Rafailidis P et al. Complement and tissue factorenriched neutrophil extracellular traps are key drivers in COVID19 immunothrombosis. medRxiv. 2020:2020.06.15.20131029. https://doi.org/10.1101/2020.06.15.20131029

11. Gavriilaki E, Brodsky RA (2020) Complementopathies and precision medicine. J Clin Invest 130(5):2152-2163. https://doi.org/10. 1172/JCI136094

12. Diurno F, Numis FG, Porta G, Cirillo F, Maddaluno S, Ragozzino A et al (2020) Eculizumab treatment in patients with COVID-19: preliminary results from real life ASL Napoli 2 Nord experience. Eur Rev Med Pharmacol Sci 24(7):4040-4047. https://doi.org/10. 26355/eurrev_202004_20875

13. Mastaglio S, Ruggeri A, Risitano AM, Angelillo P, Yancopoulou D, Mastellos DC, Huber-Lang M, Piemontese S, Assanelli A, Garlanda C, Lambris JD, Ciceri FThe first case of COVID-19 treated with the complement C3 inhibitor AMY-101. Clin Immunol 2020:108450. https://doi.org/10.1016/j.clim.2020.108450

14. Mastellos DC, Ricklin D, Lambris JD (2019) Clinical promise of next-generation complement therapeutics. Nat Rev Drug Discov 18(9):707-729. https://doi.org/10.1038/s41573-019-0031-6

Publisher's note Springer Nature remains neutral with regard to jurisdictional claims in published maps and institutional affiliations. 